\title{
La acogida de la vulnerabilidad de la infancia: la responsabilidad ética-pedagógica en la escuela
}

\author{
Daniel Gómez Ramos ${ }^{1}$ \\ ORCID: 0000-0002-4041-1512
}

\section{Resumen}

Este artículo parte de la inquietud por colocar en el centro del trabajo educativo el cuidado y la responsabilidad ante la vida de la infancia, ya que estos saberes favorecen los procesos de aprendizaje y el crecimiento personal de los estudiantes. Retomando diferentes estudios pedagógicos y filosóficos, se entiende la acogida del otro como el fundamento ético que sustenta toda relación educativa. Desde un enfoque inspirado en la investigación de la experiencia y la fenomenología-hermenéutica, se realizan conversaciones reflexivas con la directora y maestra de una escuela ubicada en contextos de dificultad. Los materiales empíricos o textos de campo creados junto a la directora/maestra han permitido pensar con la experiencia vivida y producir sentidos pedagógicos acerca de los propósitos de origen. Esencialmente, la preocupación que emerge es cómo responder a la vulnerabilidad de la infancia en la escuela, $y$, además, cómo hacerlo en mitad del flujo de actividades educativas y problemáticas sociales. A través de la indagación, se ha obtenido como resultado tres hilos de sentido o tramas conceptuales que muestran y despliegan una serie de comprensiones, disposiciones y orientaciones que pueden ayudarnos a poner en ejercicio los gestos del acogimiento en el oficio de educar. Además, el estudio profundiza en algunas de las múltiples dimensiones y cualidades de la responsabilidad pedagógica, revelando claves prácticas para establecer relaciones de cuidado con nuestros alumnos y provocar efectos positivos en sus procesos de formación.

\section{Palabras clave}

Vulnerabilidad - Acogida - Escuela - Responsabilidad pedagógica - Relación ética-educativa.

1- Universidad Nacional de Educación de Ecuador (UNAE), Azogues, Ecuador.

Contacto: danielgomezramos84@gmail.com; daniel.gomez@unae.edu.ec.

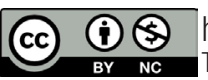




\section{Embracing children's vulnerability: ethical- pedagogical responsibility in the school}

\section{Abstract}

This article is based on the concern to place the care and responsibility towards children's life in the center of the educational work since this knowledge enhances the learning processes and the student's personal growth. Taking up different pedagogical and philosophical studies, embracing the other is understood as the ethical foundation that underpins all educational relationships. From a focus inspired by the investigation of experience and hermeneutic phenomenology, reflective conversations are held with the principal and teacher of a school located in challenging contexts. The empirical materials or field texts, created together with the principal and teacher, have allowed to think over the experience and produce pedagogical meanings about the original purposes. Essentially, the issue addressed is how to respond to the vulnerability of children in school, and how to manage it in the middle of educational activities and social problems. Through the investigation, three threads of meaning or conceptual plots have been obtained as a result that shows and displays a series of understandings, dispositions, and orientations that can help us to exercise the gestures of embracing and caring in Education. Besides, the study delves into some of the multiple dimensions and qualities of pedagogical responsibility, revealing practical keys to establishing care relationships with our students to cause positive effects on their training processes.

\section{Keywords}

Vulnerability - Embracing - School - Pedagogical responsibility - Ethical-educational relationship.

\section{Introducción}

Este trabajo es fruto de un proyecto de investigación ${ }^{2}$ que tiene el propósito de estudiar los saberes profesionales de docentes que, al establecer relaciones de cuidado con sus alumnos, hacen posible que éstos prosperen en su aprendizaje y crecimiento personal. El interés global es profundizar en la comprensión sobre la responsabilidad y el cuidado de niños y jóvenes en el oficio de educar (NODDINGS, 2003; MíNGUEZ VALLEJOS, 2012; JORDÁN, 2015). Los resultados dan cuenta del sentido ético que sustenta y guía esta actitud pedagógica y cómo influye en las relaciones educativas que mantenemos con niños y jóvenes. Otra contribución de este trabajo es la concreción de algunas de las

2- Relaciones educativas y creación del currículum: entre la experiencia escolar y la formación inicial del profesorado. Indagaciones narrativas (EDU2016-77576-P), I+D+i financiado por el Ministerio de Ciencia, Innovación y Universidades para el período 2017-2019, dirigido por el Dr. José Contreras Domingo, de la Universidad de Barcelona (España). 
disposiciones y de los gestos mediante los que se manifiesta el cuidado responsable del otro en la práctica cotidiana.

Las aspiraciones mencionadas han motivado un estudio del cuidado-responsabilidad como un saber producido en una relación de pensamiento con la experiencia vivida, un modo de saber existencial y holístico que se elabora por medio de un pensar creativo con lo que se vive (CLANDININ, 2013; AYALA, 2018). Es un saber emergente, porque dispone a interrogarse por lo adecuado ante una situación singular; pero también es sedimentado, en tanto proporciona un bagaje reflexionado y una orientación para la acción (KORTHAGEN, 2010; GARCÍA; LEWIS, 2014).

Con el objetivo de percibir las cualidades del fenómeno estudiado con mayor claridad y amplitud de matices, la indagación se desarrolló -durante el curso escolar 2016-2017en una escuela ubicada en un contexto empobrecido de la periferia de Barcelona a la que asistían niños en particulares circunstancias de vulneración. Y se hizo acompañando a una maestra -Claudia- de extensa trayectoria profesional y especialmente preocupada por el cuidado de la infancia y la responsabilidad pedagógica. Para ello se mantuvieron conversaciones hermenéuticas (SIERRA; BLANC0, 2017) con la maestra, que también es directora de la escuela y co-creadora del proyecto educativo del centro, profundizando a lo largo de un curso escolar en las inquietudes de este estudio y ampliándolas.

La intención de las conversaciones hermenéuticas no fue ahondar en los saberes propios de la maestra/directora ni identificar y documentar las buenas prácticas de su proceder, sino recibir sus formas de hacer y de pensar como situaciones experienciales (CONTRERAS, 2013). Es decir, como acontecimientos novedosos que requerían ser pensados por el investigador para producir los sentidos y los significados que revelarían las diversas dimensiones pedagógicas que la responsabilidad y el cuidado verifican en el mundo empírico (JAY, 2009).

\section{Marco teórico}

El encuentro con la vulnerabilidad de un niño supone un acontecimiento ético puesto que, desde su singularidad, solicita ser ayudado mediante una respuesta concreta y situacional: reconocerlo, acogerlo sin condiciones y ofrecerse a acompañarlo (BÁRCENA; MĖLICH, 2014). La relación pedagógica hunde sus raíces en la responsabilidad ética, en la radical dependencia del otro de nuestra escucha, atención y cuidado, y de que nuestra respuesta debe hacerlo progresivamente responsable de sí y del otro. Según Lévinas (1977), el lazo social se anuda en la preocupación y ocupación por el prójimo, pues lo que da sentido al Yo es cuidar del otro; de hecho, la responsabilidad es la estructura esencial, primera y fundamental de la subjetividad.

¿Qué implicaciones pedagógicas tiene esta disposición subjetiva? ¿Mediante qué gestos se materializa en la relación educativa? ¿Cómo opera el lenguaje ético del cuidado responsable? ¿Qué efectos tiene en la subjetividad del niño?

Tomar conciencia de lo extraordinario de la llegada de un niño o joven implica dejarse conmover por la vulnerabilidad de su condición, lo cual demanda al educador volverse sensible, vulnerable y receptivo a la experiencia afectiva y emocional que abre al 
yo al encuentro con la alteridad. Dice Van Manen (2015) que la responsabilidad pedagógica brota en uno cuando percibe las necesidades de un niño o joven y se siente reclamado a responderlas haciéndose cargo de su vulnerabilidad. Sólo entonces, siendo sensible a la fuerza de su fragilidad, sintiendo su voz como una interpelación y experimentando a través de la responsabilidad la autoridad que el niño o joven concede, el adulto está en posición de hacer algo cuidadoso por él.

El artículo que sigue centra su foco de interés en los gestos, tonalidades y disposiciones que hacen posible una ética de la acogida (DERRIDA, 1998) en el oficio educativo. Entendiendo la oferta de hospitalidad no bajo el orden de una legislación o normatividad sino desde la pregunta por cómo tratar adecuadamente al otro (LÉVINAS, 2005). La no-tematización de un niño es condición para la aparición de su singularidad, de la proximidad con él y de su deseo de aprender. El educador que, inicialmente, se vulnera en su fragilidad se hace más receptivo a la contingencia y la necesidad de otras vulnerabilidades. A partir de fragmentos de conversación con la directora de la escuela, se analizan los modos en que ésta se convierte en lugar de cobijo, resguardo y amparo de la fragilidad de la infancia. Cuando la escuela se centra en las relaciones humanas y proporciona una atmósfera de cuidados, favorece los aprendizajes curriculares y permite que los niños salgan de su posición social.

\section{Metodología}

Dada la complejidad epistémica del saber pedagógico, esto es, que no se deja reducir a técnicas cerradas y procedimientos acabados pues su carácter es holístico, integrado, relacional, emocional, corporal, valorativo y ético, se decidió configurar una metodología inspirada en la investigación de la experiencia educativa y en la fenomenologíahermenéutica (GADAMER, 1977; DEWEY, 1998; VAN MANEN, 2003; CONTRERAS; PÉREZ DE LARA, 2010) con el objetivo de pensar con la experiencia y producir sentido. Esta disposición subjetiva de indagación supone habitar la escuela como sujeto de exposición y recepción de la alteridad de los otros, del mundo y de uno mismo, implica atender y captar el fenómeno como algo que, al acontecer, provoca en la sensibilidad una inquietud educativa. Un afecto que da forma a un signo o hilo de sentido que solicita de la conciencia una significación mediante el pensamiento (ARBIOL, 2018).

Si algo resuena subjetivamente es porque la conversación funciona como una experiencia vivida que despierta una pregunta o conecta con una necesidad, signos que hablan de una búsqueda de sentido pedagógico. El hilo de sentido es experimentado por la reflexividad como el acontecer de una exterioridad que nos deja pensando o que nos da que pensar. Desde diversas orientaciones (KORTHAGEN, 2013; ALLIAUD, 2010; BIESTA, 2017) se entiende el acontecimiento como un encuentro entre la experiencia y el pensamiento que tiene el poder de extrañarnos de lo conocido, desplazarnos del propio punto de vista, incomodar nuestros presupuestos y hacernos dudar de nuestras palabras. Lo que acontece en la experiencia de conversación con Claudia contiene la posibilidad de producir una nueva elaboración de los significados de nuestras acciones y actitudes. 
Los momentos metodológicos pueden enumerarse con la siguiente secuencia: (1) percepción del fenómeno en conversación; (2) escritura en el diario de campo o grabación y transcripción de la conversación; (3) dilucidación de interrogantes e hilos de sentido; (4) construcción de fragmentos de conversación -textos de campo-; (5) amplia consulta de corpus teórico y (6) comprensión a través del ensayo como modo de interpretación y reflexión -textos de investigación-. Durante el proceso se llevó a cabo una triangulación ambiental (OKUDA; GÓMEZ, 2005): al regresar cada día a la escuela y a la conversación con Claudia, lo escuchado y analizado volvía a contrastarse y dilucidarse dando origen también a una nueva revisión y alimentación teórica para, finalmente, desembocar en el tratamiento investigativo como una comprensión más profunda y contextualizada del tema estudiado. De esta manera la escritura resultante del estudio se torna un producto confiable en tanto en cuanto permite al lector o lectora reconocer en el texto sus inquietudes $\mathrm{y}$ hacerse sus propias preguntas.

Después de la percepción del fenómeno en la conversación, en mi diario de campo tomaba notas descriptivas de las palabras que compartía con la maestra/directora, y de lo vivido y de lo pensado junto a ella en la escuela. A partir de esas anotaciones y de las transcripciones de las grabaciones, relataba un Fragmento de Conversación (FC): un texto de campo que no lo dijera todo de la experiencia, que no clausurara su potencia significativa, pero cuya lectura tuviera la capacidad de suscitar los interrogantes que se me habian desvelado (ZAMBRANO, 2011).

Un fragmento de conversación muestra un material sensible con el que seguir elaborando un pensar con la experiencia con el que trazar diversos caminos de escritura mediante los que ir ahondando reflexivamente en las dimensiones pedagógicas que había implicadas en el fenómeno registrado. El diálogo entre los textos del material experiencialsensible y la documentación de literatura teórica fue descubriéndome temáticas de investigación, enfocando con precisión mis preguntas y captando los hilos de sentido susceptibles de ser explorados.

Para los textos investigativos se empleó la escritura ensayística (ADORNO, 2003; LUKÁCS, 1970), que permitió sostener un trabajo de ampliación y profundización en el abordaje de las cuestiones educativas que residian en los textos compuestos durante la estancia en la escuela y los encuentros con Claudia. Porque el ensayo procede indagando experimentalmente con el tema de estudio desde diversas vertientes y lo hace estableciendo con lo vivido una distancia poética: creando, revelando o trayendo al presente algo valioso (AGAMBEN, 2005). El lenguaje del ensayo es un lenguaje con alguien dentro, un lenguaje frágil y heterogéneo, cuyas palabras se quieren evocativas pero siempre preocupadas por la pluralidad y la transferencia de conocimiento de la investigación educativa.

\section{Resultados y discusión}

Como resultado se presentan tres hilos de sentido tejidos en una trama de categorías cuya elaboración fue realizada a partir de la articulación entre: (1) los propósitos de la investigación; (2) la experiencia vivida en la escuela; (3) la identificación de diferentes signos de los acontecimientos y (4) la elaboración conceptual (DELEUZE; GUATTARI, 
2013) mediante un pensamiento entendido como producción de nuevos efectos de sentido que tratan de hacer justicia a la multiplicidad semántica de lo real (LARROSA, 2010). Dado que el estudio es más amplio, a continuación se muestran algunos de los asuntos más relevantes sobre los que se ha decidido indagar con mayor exhaustividad.

\title{
La escuela como refugio
}

\begin{abstract}
Tenemos claro que antes es el "estar bien" que el trabajar. Con lo cual si la dinámica del grupo está bien, trabajamos, si la dinámica no está bien, trabajamos la dinámica. Y luego, cuando podemos, atendemos las cuestiones personales. Por eso yo no diría la palabra "cambiar", porque nosotros no podemos cambiar casi nada de su entorno social. Lo que sí que podemos hacer es que se sienta a gusto para poder estar aquí. Que se encuentre aquí, porque aquí podemos ofrecerle un espacio. Ellos saben que cuando entran aquí tienen un espacio donde pueden ser.

¿Qué le podemos ofrecer aquí? Un espacio donde pueda crecer, un espacio donde pueda hablar, donde se pueda comunicar, donde se pueda relacionar. Y siempre les podemos ofrecer otro tipo de relación. Que sepan que hay otras maneras de relacionarse en el mundo, que no son solamente las que conocen en casa.

Ellos saben que nos encuentran, a las maestras y los maestros, saben que estamos para ellos. Además, lo verbalizamos muchas veces: "Yo lo que quiero es que tú te sientas bien aquí. Ya sé que no estás bien, que tienes algún problema, pero yo aquí quiero que estés bien. Fuera no puedo meterme con tu familia, no puedo cambiar a tu mamá y a tu papá. Pero lo que sí puedo hacer es ofrecerte aquí otra cosa”. (CLAUDIA_FC4).
\end{abstract}

Los seres humanos necesitan habitar en espacios inmunológicos efectivos para existir como quienes realmente son (SLOTERDIJK, 2014). La supervivencia humana depende de la contención de estos espacios de protección. Atender a un niño es atender frágilmente su fragilidad. Gesto ético que funda la relación pedagógica. Como si la pedagogía consistiera en esperar el consentimiento del otro para sentirnos con el derecho de hablarle. Como si la pedagogía consistiera en entregarse hospitalariamente sin imponer condiciones al otro y crear circunstancias para que pasen cosas entre nosotros.

La escuela en su origen es continente de la existencia que separa la infancia de la insignificancia. En este sentido los muros de la escuela delimitan y definen dos espacios diferentes. Diferencia de objetivos, pero, más importante, diferencia de gestualidades. La palabra griega scholè quiere decir ocio, hacer algo sin ninguna recompensa. Mientras que negocio viene de nec-otium, sin ocio, hacer algo por dinero o no sin recompensa. La escuela se inventó como fuente de tiempo libre para el estudio y para la práctica concedido a personas que no tenían derecho a él. Lo que realmente significa estar en la escuela o dentro de la escuela es tiempo que libera las vidas del negocio. Según Masschelein y Simons (2014), tiempo no productivo, indefinido, al que no se puede tener acceso de otra manera. El tiempo de la familia y del mercado laboral ya está ocupado de modos diversos.

La forma escolar deja en el exterior la dispersión ruidosa y las hostilidades de la sociedad. Es un espacio público que permite una experiencia del tiempo distinta. La escuela reúne a pequeños y a grandes para poner en el centro el sentido de las biografías personales 
y los bienes comunes. Su función es doble: atender a los recién llegados para inscribirlos en una cultura y cuidar al mundo de la potencia renovadora de la natalidad (ARENDT, 1996). Su realización depende de que sus fronteras expulsen el círculo económico y los intereses del mercado del tiempo escolar. Tiempo liberado de toda lógica de rendimiento y disponible para el estudio y la socialidad como medios puros (sin finalidad, son valiosos por sí mismos).

El recogimiento, la demora y la proximidad son la manera de ser del ser humano como lo son de la escuela. Lo escolar funciona como refugio del niño frente a una sociedad que pretende instrumentalizarlo lo antes posible. Scholè sería, siguiendo a Esquirol (2015), un tiempo y un espacio de recogimiento dedicado a mirar y a observar el mundo, para tenerlo o tocarlo con la mirada y para seguirlo (que es lo que significa observar) y orientarse en él, dado que, la mirada y el seguimiento son modalidades de la orientación necesaria para vivir.

Hay un niño que viene y me dice que le duele algo. Le puede doler de verdad o no, pero lleva tres días seguidos. ¿Qué está pidiendo este niño? Está pidiendo que lo atiendas. A él y a nadie más. Entonces lo atiendo, estoy un rato con él. Le pongo una crema, le pongo no sé qué. "Límpiate un poco las manos y verás cómo se te pasará". "Ah, te voy a poner una crema que te irá super". Tenemos varias cremas homeopáticas, pues un poquito de cremita. 0 un desinfectante. 0 una tirita. Y le limpias la herida. Y ya está. Ya saben dónde pedir. Le acabo de poner la crema y le digo: “¿te sigue doliendo?”. Y me dice: “ya no porque me has puesto la crema”. Creo que no somos conscientes de la importancia del tiempo de atención a los niños.

Nos vienen a pedir que les curemos algo que no se han hecho aquí. Se lo han hecho en casa. Una quemadura, una rascada de uña. “¿Pero esto dónde te lo has hecho?”. Siempre lo pregunto. La mayor parte de veces se lo han hecho en casa. Y es una herida que no se ve. "Me duele aquí, en el cuello". Te señalan un punto de su cuerpo. "Venga va, te haré un masaje y verás qué bien te irá". Le dedicas cinco minutos. Y luego le preguntas: “¿te quieres quedar aquí o te quieres ir a clase?”. "Me voy". La mayoría de veces se van, porque solamente quieren ese momento de contacto, de relación, de vínculo, de ser atendidos. Curas una herida de donde sea, de cualquier tipo que sea. Yo creo que la mayor parte de niños saben que aquí encuentran eso. (CLAUDIA_FC5).

La escuela ofrece a los niños y niñas un espacio donde experimentar con las relaciones humanas y con los aprendizajes curriculares en una atmósfera de cuidados. "Que se sienta a gusto para poder estar aquí. Que se encuentre aquí, porque aquí podemos ofrecerle un espacio [...] donde poder ser y donde poder estar". La escuela dona un tipo de cobijo que ampara la fragilidad de la infancia de las fuerzas que la ponen en peligro. Actúa como un refugio para el niño al levantar un muro entre las influencias de su contexto y la orientación de su voluntad hacia el estudio y la educación.

El umbral que separa la calle o la familia y la escuela imprime en los cuerpos una sensación liminar. El tránsito entre el afuera y el adentro busca una variación del estado de ánimo. Quien traspasa la puerta de esta escuela está sometido a la posibilidad de una transformación. La transición es una negatividad porque hay un padecimiento inherente. 
Un enfrentamiento con la otredad de nosotros mismos. Aunque lo que el niño halla en esta escuela es hospitalidad, es decir, el don de una aceptación sin condiciones (DERRIDA, 2000). Aquí el padecimiento quiere decir: efecto de los afectos que curan heridas. "Vienen a pedir que les curemos algo que no se han hecho aquí. Se lo han hecho en casa. Esto es lo metafórico y lo paradigmático. [...] Y es una herida que no se ve. [...] Y le limpias la herida".

Abrazar, cobijar, recoger y acompañar serían las gestualidades fundamentales de una pedagogía del don. También la palabra acoge y contiene, sin buscar productividad. La palabra permite la demora y la detención. La palabra se ofrece como espera y permanencia. A través de sus gestos son las maestras las que dan de sí mismas. Y lo primero que dan es lo más propio que poseen: su tiempo. El cual es antes que suyo, el tiempo del niño. No es una transferencia de minutos y de horas, sino que el propio tiempo es una exapropiación (DERRIDA, 1995). La experiencia del tiempo que importa es la del niño, atenderlo se impone al narcisismo.

Que la escuela sea un buen lugar para vivir exige que la lógica del resultado quede fuera de ella. Dicha lógica lleva a la desvitalización de los sujetos en cuanto los inscribe en una alienación funcional. El mercado laboral tiene prisa por adultizar a los niños en una obsesión patológica por el empleo. La aceleración actual acorta la infancia en pos de su ejecución como sujetos de rendimiento y consumo. La optimización académica del dominio neoliberal hace que pequeños y grandes acaben por no sentir su propio cuerpo (HAN, 2017). El valor inicial del dispositivo escolar es funcionar interrumpiendo el curso normal de las cosas y la desigualdad que genera. El gesto puramente escolar, para decirlo con Masschelein y Simons (2014), es llevar a los niños al tiempo presente y liberarlos tanto del lastre potencial de su pasado como de la presión potencial de un futuro ya proyectado (o ya perdido).

"El gesto esencial se puede nombrar con el verbo amparar. Amparar significa 'proteger parando o deteniendo algo'. El desamparo consiste en quedarse sin protección, sin ayuda o sin asistencia” (ESQUIROL, 2015, p. 49, énfasis del autor). El amparo primordial es el que nos ofrece el prójimo con y desde el afecto. El proximus, el que está más cercano, nos afecta y se abre a nuestros afectos. El amparo inicial procede de la madre que se da a sí misma al recién nacido. Los brazos son cuna y primer continente de la existencia humana. Recogen, mecen y consuelan de la sensación de anonadamiento (conversión en nada) del arribante. El amparo efectúa la condición humana al resguardar al niño de su naturaleza de abandonado a sí mismo (ARENDT, 1996).

La madre responde a la llamada del hijo, compromiso que la dota de subjetividad. El niño resguarda y ampara a su madre al traspasarle la responsabilidad que a él le pertenece. El uno es sujeto del otro (LÉVINAS, 2000). Atadura, sutura, juntura. La madre es la casa del niño y el niño es la casa de la madre. Aunque el reparto de obligaciones en la relación es asimétrico. Es mayor la vulnerabilidad del otro y hemos de cobijarle en nuestro cuerpo. Ternura, suavidad y sosiego serían las tonalidades de la acogida. "A mí me importa más cómo se siente el niño al venir aquí. [...] ese momento de contacto, de relación, de vínculo, de ser atendidos". La educadora es palabra de alivio, calienta el cuerpo y el espíritu. 
La vocación del otro se dedica a amparar la flaqueza del niño para que renueve sus fuerzas (PATOCKA, 2004). El acompañamiento alimenta al niño para que recobre la firmeza y cure sus heridas. “¿Qué está pidiendo este niño? Está pidiendo que lo atiendas. A él, a él y a nadie más. Entonces lo atiendo, estoy un rato con él". La pregunta que se hace Claudia es esencialmente ética y dispone desde la receptividad a la acogida. La actitud hospitalaria de la educadora, de por sí, es curación y enseñanza. Parte de la suposición de que todo ser humano es frágil y está amenazado por azarosas rupturas. La receptividad de la poderosa mirada y voz de un niño requiere que nos vulneremos. Amparar su presencia requiere que, antes, nos debilitemos. Condición de ser hospitalario es la no-resistencia a perder una parte de Yo.

"Saber acerca del otro" lo vuelve transparente, lo despoja del enigma que lo singulariza (LÉVINAS, 1977, p. 207). Se trata de conservar una prudente distancia con el niño en el seno de una proximidad afectiva. Él debe continuar como desconocido y nosotros padecer la negatividad de su diferencia absoluta. La fantasía de saber quién es el otro elimina la lejanía, pero no construye la cercanía. Pensar la relación con un niño se ha de encomendar a la experiencia de la irrupción de lo distinto. El pensamiento educativo ha de encauzarse a lo todavía no contemplado (DELEUZE, 1987). De lo contrario, corremos el peligro de suplantar su identidad con la proyección de una imagen temática.

¿Qué está pidiendo este niño? ¿A qué nos solicita su llamada? Darnos cuenta de nuestra fragilidad vulnera la coraza narcisista y abre la puerta de nuestra casa al niño como extranjero (LÉVINAS, 1977). Nos sensibiliza para registrar los signos que expresa el cuerpo del niño: su voz, su mirada... Signos que se sustraen a toda categorización, resisten desubicados a la percepción. Un cuerpo es un excedente de significantes que no se deja reducir a una información unívoca. Lo que porta un niño es ambiguo, escapa del orden clasificatorio. Su voluptuosidad es más grande que Yo.

El encuentro con el cuerpo del otro es un acontecimiento corpóreo. Su secreto atraviesa nuestros conceptos y no da lugar a descubrimiento alguno. Permanece oculto, deslocalizado, el niño llega con sus voces y sus miradas solicitando atención. "Creo que no somos conscientes de la importancia del tiempo de atención a los niños”. Una atención detenida, pues la relación es tensión de extrañeza que causa asombro. Pide tiempo para demorarnos en la contemplación que invoca en el niño su otredad. El encuentro se produce con alguien o algo radicalmente distinto, ajeno a nuestras figuraciones (LÉVINAS, 1993). La exterioridad del niño es padecimiento. No podemos conocerlo en el sentido de identificarlo. Si lo hacemos lo cosificamos fijando su devenir inédito. Lo atrapamos en etiqueta y le arrancamos su nombre propio. El rostro de un niño es dolor de lo inhóspito. Acontecimiento ético que nos obliga a un desaprendizaje: vaciamiento para un pensamiento de la respuesta adecuada.

La escucha es escucha atenta cuando escuchamos lo desconocido del otro. El ruido de la pedagogía de resultados cancela la posibilidad de escuchar con detenimiento. El tiempo acelerado vuelve imposible la ética del cuidado y el estar a la escucha (HAN, 2013). En la relación educativa el tiempo que importa es el tiempo del niño. La finitud humana inscribe en el sujeto lo que más le pertenece: su tiempo. El tiempo del educador es el tiempo del educando, el primero está al servicio del segundo. Estar a la escucha 
significa, para Lévinas, “[...] un excedente de conciencia que supone la llamada del Otro. Ser atento es reconocer el señorío del 0tro, recibir su mandato o, más exactamente, recibir de él su mandato de mandar" (1977, p. 196). Recibir de él su mandato de pensar qué es lo pedagógicamente adecuado para su humanización. Recibir de él su consentimiento para entrar en relación educativa.

\section{El lenguaje de la proximidad}

La acogida es un trabajo de todos los días. [...] Cuando llegan los niños, este espacio se convierte en escuela. Cuando Andrea me mira, me convierto en maestra. Cuando Nicolás se presenta en la puerta, intento no verlo como un caso de inclusión. Es Nicolás, es Andrea, es Lucía, es Mauricio [...]. Tienen la cualidad de confrontarme con mis propias impotencias. Intento escucharles, intento hablarles, y relacionarme con ellos ante todo. [...] Creo que es poner palabras a las cosas lo que nos permite estar juntos. Poner palabras es como salir del aislamiento y protegernos entre nosotros. [...] Los niños son muy vulnerables. Todos lo somos, pero ellos más. (CLAUDIA_FC8).

El extranjero arriba con necesidad de alojamiento y, al entrar en nuestra casa, la convierte en hogar y a nosotros en sus huéspedes (DERRIDA, 2000). El Yo enmudece frente a la distancia del extranjero. Tanto su palabra como su silencio zarandean cualquier intento de controlar el encuentro. Sentimos la alteridad de su presencia, nuestra actitud es de escucha pasiva.

La tarea de la pedagogía vendría a consistir en abrir la atención al niño como un prójimo distinto. Si la política y la economía actuales centran la atención en el ego, ésta se pone al servicio de la autoproducción y la competencia: el prójimo se degrada a mero espejo en el cual uno se refleja (HAN, 2017). La consecuencia es la primacía y suplantación del nombre propio por una descripción o por un número. La descripción suaviza el trato y acelera los recorridos de los sujetos por el sistema. El número nos inmuniza frente al otro y lo introduce en el ámbito de la eficiencia calculable. Las dos operaciones buscan homogeneizar lo excepcional. Expulsar las subjetividades que no se acomodan a los recorridos ya diagramados. El recién llegado es, no obstante, una anomalía.

La realidad es que podemos rompernos. Somos frágiles frente al otro y somos frágiles para el otro. Uno solo no puede y necesita del don de los demás. En esta limitación del no poder se despierta el deseo del otro. Deseo del tiempo del otro que será donación. Donación gratuita y contraria al tiempo del Yo que se extingue en sí mismo (LÉVINAS, 1993). Nuestras imposibilidades nos introducen en el movimiento excéntrico de lo humano, o sea, en dirección hacia las personas y las cosas del mundo. Esta es la huella de la vulnerabilidad que nos aproxima, el vacío que desea el nosotros. El surgimiento del deseo del prójimo libera al Yo de quedarse enredado en sí mismo y lo conduce al contacto con la alteridad. El eros que nos despega del Yo -autocentrado- llevándonos al otro es lo único que puede salvarnos de la depresión (crisis nerviosa, infarto psíquico) y salvar al otro de ser abandonado a su propia suerte, a sus recursos.

Que alguien es prójimo quiere decir que estamos enlazados a él por un lenguaje de la responsabilidad (HAN, 2017). Antes que nada, acogemos al otro con la palabra que hace de lazo. Lazo asimétrico pues somos quienes se hacen cargo de la recepción (no de 
su dominación). Lo recibimos en nuestro cuerpo que es casa de palabras, según Lévinas (2005), el lenguaje original es amparo primordial del otro. La palabra permite la cercanía, su sentido es la relación ética $y$, después, la relación educativa.

La no-tematización de un ser humano es condición para la invocación de la singularidad del prójimo y la cercanía con él. La cercanía tiene en sí misma significado y se expresa en la caricia. La caricia es búsqueda sin fin del otro inaprensible. Y la palabra es el vehículo de la caricia; pero también la mirada que contempla con atención. Sentimos el cobijo en el lenguaje de alguien cuyo tacto nos aproxima sin reducir lo que somos a un tema. La mirada ética es sensible a la infınitud del rostro, en lugar de identificarlo crea un acercamiento.

Somos sensibles a la fragilidad de un niño cuando somos deferentes hacia él. Su presencia porta en sí misma un sentido indescifrable que demanda la cercanía de un lenguaje de contacto. El tacto de un cuerpo sensible, vulnerado, que no es indiferente a la necesidad de otro cuerpo. El tacto de un pensamiento que piensa al otro dejándose afectar por el peso de su vida. Las palabras acarician cuando consideran la primacía del prójimo y su infınitud plantea una pregunta. ¿Qué necesita el otro? ¿Cómo experimenta él la situación? ¿Cuál es la respuesta adecuada?

Pensar el encuentro es pensar al margen de la relación de poder y de la relación de saber: es pensar la relación entre deseos. "En el lenguaje cotidiano nos aproximamos al prójimo en lugar de olvidarlo en el 'entusiasmo' de la elocuencia”, dirá Lévinas (1997, p. 156). La relación ética funciona como conversación entre iguales: me dirijo a ti como a cualquiera, como si fueras un igual. Presupongo contigo una igualdad anterior a tu llegada. Una igualdad que abre el acogimiento. Somos hermanos en el sentido que hay un lazo original que nos sujeta. El lenguaje de la proximidad es un diálogo que comienza como pre-logos, antes del discurso o palabra de acogida y promesa. Com-promiso no recíproco; el que importa eres tú, ¿cómo puedo atenderte?

\section{Estar a la escucha}

Si el verbo amparar significa proteger deteniendo algo, lo que detiene es el mal como aquello que resulta amenazador o dañino. Y si el amparo de alguien se efectúa por mediación del lenguaje, nuestra palabra es amparo de la palabra del otro. La palabra es una casa que protege, arropa y reconforta. La palabra hace las veces de abrigo y teje la acogida.

Para mí el centro es la relación, el conocimiento va pegado a ella. Primero tiene que haber un buen ambiente, y cuando lo hay puedo trabajar los contenidos. Se trata de crear circunstancias para que nos pasen cosas. Hay niños que necesitan pasar por este despacho antes de irse al aula. Los que lo saben, lo hacen. Vienen por la mañana a ver quién hay aquí, a saludar. Tú notas que no viene bien y dices "va, quédate un rato aquí y ya subirás luego". Esto sucede muchos días: si yo veo y capto que alguien viene mal, se lo digo, se lo ofrezco yo. Si no, lo buscan. A veces me buscan, o a la Domi, lo buscan porque lo necesitan.

Ellos encuentran que los atiendes, o no les dices nada, pero les permites. Les permites un rato para ellos. Me imagino cuando un astronauta tiene que pasar por ese tubo donde hacen la 
descompresión. A veces este espacio es eso, vienen aquí, tienen que pasar por otro espacio de transición antes de ir a clase. Esto hay que poderlo permitir, entonces hay niños que a las 11 me buscan o me ven por el pasillo "quiero irme contigo un rato". A veces los cojo y a veces no, depende. Si veo que es un capricho no, si veo que yo noto que hay algo ahí, que capto, les digo que sí. Les digo "sobre todo, pide permiso que estás un rato conmigo" y lo permitimos todos que sea así.

Me he ido dedicando muchos años a cuidar niños a ratos y se ha ido creando este espacio. Hay momentos que el niño no quiere estar ahí, no encuentra su lugar en su grupo, por lo que sea, por cómo viene, por cómo ha dormido, por cómo no ha dormido, por cómo etcétera. No está en ese momento para estar en clase, en grupo, se pone nervioso.

Por ejemplo, si no han comido por la mañana, yo pienso que es un fallo que no desayunen antes de venir. Muchos niños no comen nada, y como yo sé que me pongo de muy mal humor si no como nada, al niño le pasa lo mismo. Muchas veces les damos galletas o les daba galletas por eso, azúcar, algo, porque no han comido nada, entonces se sienten mal y no saben por qué y muchas veces porque tienen hambre, simplemente. 0 no había comida o no había leche en su casa.

Muchas veces les pregunto “¿has desayunado?” Por la mañana si alguien viene y no está bien siempre hago la misma pregunta, “¿has dormido bien? ¿has desayunado? ¿has tenido algún mal rollo antes de salir de casa? ¿te ha pasado algo viniendo?” Son las preguntas básicas, y allí empezamos, “¿te hago una manzanilla?” Muchas veces dicen que sí, igual no les gusta y no se la toman, pero alguien ha estado por mí un rato y me ha hecho algo para mí. (CLAUDIA_FC7).

La primera palabra del infans -el que aún no habla, o mejor, el que habla otra lengua-, es un ruego. La palabra que hospeda esa petición (ese rogare) es lengua materna. El pequeño llega con el llanto y el grito sonando en la intemperie de la noche. El grande da una casa donde ampararlo del mal y del sufrimiento. "Hay críos que necesitan pasar por este despacho antes de irse a la clase. [...] Lo buscan porque lo necesitan. [...] Les permites un rato para ellos”. La esencia de la acogida incondicional, ¿no sería la función afectiva de un lenguaje que diga la verdad?

El despacho de Claudia es objeto de una metamorfosis causada por la potencia de los deseos de los niños de la escuela. La "cápsula de descompresión” opera simbólicamente como umbral que marca una variación en el estado anímico. Reaviva la fuerza vital de los niños, les devuelve el buen ánimo para la relación. Se experimenta una transición entre las preocupaciones de los pequeños y su disponibilidad a la socialidad y el estudio.

Lugar hecho de lenguaje, pues lo que permite la transición es la palabra (LÉVINAS, 1977). Y la palabra es transición pero, también, posada. Lugar de pausa, detención y recogimiento cuyo sentido es atender el grito comprimido del niño y dar tiempo a su descompresión en plegaria. Solicitud y cuidado por el niño que necesita detenerse para recomponer su firmeza y su salud. Demorarse en la escucha aunque no haya nada que decir. Dejar que emerja el inter-rogare y la pregunta: ¿Cómo estás? Si se dice con franqueza, la palabra apacigua el ánimo.

"Les pregunto [...] ¿has dormido bien? ¿has desayunado? ¿has tenido algún mal rollo antes de salir de casa?, ¿te ha pasado algo viniendo?". La petición del niño es demanda de una respuesta de amparo. La petición de la maestra es la verificación de su gesto ético. Juntos nos interrogamos en un diálogo que es una oración donde nos decimos 
y nos pensamos en compañía. La plegaria se manifiesta como súplica de acogimiento porque asumimos estar en precariedad. Tenemos el lenguaje para rogar ante la inmensidad y para ampararnos de ella en un refugio.

El encuentro con el prójimo es una experiencia profunda a la que es inherente la vulneración y la conmoción. El don de la palabra de acogida sólo es posible si la biografía del otro nos concierne (BUTLER, 2006). Sólo si estamos sinceramente preocupados por su desarrollo, él sentirá las consecuencias de nuestro cuidado. Nuestros juicios, especulaciones o discursos hacen que el otro pierda su figura y mata algo que es suyo. En cambio, la vulneración nos instala en nuestras heridas que son las puertas que se abren al prójimo. La herida es brecha en la carcasa del Yo aislado a través de la cual acceden la voz y la mirada del otro. El encuentro con él depende de nuestra capacidad de que su presencia nos conmueva.

El propio discurso nos protege de la irrupción de lo extraño pero hace desaparecer la singularidad. La esencia del lenguaje como acogida sortea la prepotencia por la senda de la sensibilidad y la proximidad (LÉVINAS, 2005). Nuestros juicios eliminan toda distancia porque se apropian cognoscitivamente de lo otro pero no generan ninguna cercanía corporal. La egológica repetición de la voz propia impide la actitud de escucha solícita. Quien se vulnera en su fragilidad se vuelve receptivo a las señales de otras fragilidades.

Quizá por eso Claudia dice "notas cuando no viene bien" o "noto que hay algo ahí" o "capto que": expresiones que indican la activación de un cuerpo sensible a las vibraciones de los afectos. Su actitud receptiva es invitación a la exclamación del ruego del niño. El cual se siente bienvenido al recibir la afirmación de su alteridad. Instalar la herida en la presencia dispone a la capacidad empática. "Como yo sé que me pongo de muy mal humor si no como nada, al niño le pasa lo mismo”. Las especulaciones narcisistas se retiran para dejar espacio al cuerpo como lo distinto. Prestar atención a lo que dice alguien puede bastar para curar y recobrar cierta salud. Quien escucha sin reservas se vuelve un cuerpo de resonancias donde el prójimo puede liberarse hablando. "Lo buscan porque lo necesitan [...] hacen la descompresión [...] espacio de transición antes de ir a clase”.

El tiempo que Claudia da a los niños que lo necesitan es el único tiempo que importa. El tiempo del otro es aquel que compone relaciones humanas, por eso es tiempo bueno. En la pasividad de la paciencia el oyente se pone a merced del otro sin reservas; quedar a merced es otra máxima de la ética de la escucha y es lo único que impide que uno se complazca de si mismo, pues el ego no es capaz de escuchar (HAN, 2017).

El miedo y el sufrimiento de los niños son motivo de sincero respeto por Claudia, ella se vacía para albergarlos y protegerlos. Al disponerse a la escucha, establece un hilván entre su propio sufrimiento y el de los niños. Esta escuela es un nosotros de formas de vida heterogéneas y dependientes entre sí. Esta escuela es cultura de acogida que produce lo humano en los individuos. El gesto humano por excelencia es la atención en la proximidad que no traiciona la alteridad.

El buen educador cuida del otro porque el efecto de su amparo es beneficioso. La relación ética es sentido de humanidad porque busca ocuparse de quien lo necesita. Así encontramos que atender y asistir significan detenerse al lado de alguien. "Estar al lado ya es el modesto suelo que se ofrece", dice Esquirol, "[...] al abrigo de la proximidad se inician la confianza y la cura” (2015, p. 88, énfasis del autor). 
Cuando una infancia se expresa, nos es confiada. Todos sus gestos son signos que se dirigen a nosotros y de los que nunca quedaremos dispensados (DERRIDA, 1998). El sí dicho al niño es ilimitado, de ahí que nuestra subjetividad se produzca en el apremio de la destinación que a él nos lleva. Y lo absurdo es que no somos nosotros sino él quien puede decidir decir sí. Según Derrida, "la subjetividad se define como hospitalidad. Separación sin negación y, por ende, sin exclusión” (1998, p. 76). La responsabilidad llega a nosotros pero a él le corresponde su consentimiento.

¿Qué podemos hacer sino abrir el lenguaje de la intimidad que es nuestra casa? Una casa finita pero capaz de albergar la infinitud de un ser humano. Esa es la esencia de la bondad de un lenguaje donde el otro habita inalcanzado por la racionalidad. Y es que en el recibimiento de una criatura, recibimos al infinito irreductible al cual nuestra espontaneidad se subordina. Quizá necesitamos desaprender algunas cosas para aprender el gesto de alojar. Desalojar el primado de las propiedades y las expectativas para permitir la visitación de un niño.

¿No es esta la deferencia que inspira la trascendencia de un encuentro pedagógico? De un encuentro que fractura el pensamiento mismo de la hospitalidad. Pues la llegada del niño precede a nuestro ofrecimiento, él no llega porque lo invitamos. Vivimos su revelación como una experiencia perturbadora. Deja en nuestro cuerpo una huella, una marca, un trazo, cuyo sentido deberemos trabajar más tarde. Y lo trabajaremos lo más fielmente posible a una realidad, la del otro, que excede toda comprensión exhaustiva.

Llegada inesperada e incluso temida, esperada más allá de lo que comúnmente llamamos espera. La visita del huésped es visita mesiánica. Su visitación inaugura en la relación una inversión de mis poderes. Todo recién nacido es mesías que trae la buena noticia de un nuevo comienzo: el reino de dios, es decir, el reino del otro (LÉVINAS, 1977). Lo que quiere decir que la presencia de una criatura nos sustituye en el centro de nuestra alma.

El tiempo de la relación consiste, por así decir, en ser espera paciente del prójimo. Una paciencia desmedida pero una espera sin esperado (DERRIDA, 1998). Y es que su piel es vulnerabilidad infinitamente expuesta que precisa ser amparada independientemente de sus cualidades.

La acogida absoluta exige que abramos nuestra casa al extranjero con nombre de pila. Y que demos lugar no sólo a él sino al otro absoluto en él, desconocido y anónimo; dejarlo llegar, dejarlo venir (DERRIDA, 2000). Y lo que resguarda la hospitalidad junto con el huésped es la hostilidad que él porta en sí mismo. Hostilidad que sacude el dogmatismo de nuestra estructura, hostilidad que hace que todo niño resista como porvenir. En tanto porvenir, el niño es enigma que no debemos plegar a nuestras proyecciones educativas. En el encuentro, la hostilidad custodia la singular e infinita novedad que es él. Acoger su hostilidad, por tanto, desarma el formato único del encuentro escolar. Dándonos la posibilidad de pensar múltiples modos de componernos juntos.

\section{Conclusiones}

Pensar la acogida como acontecimiento ético (BÁRCENA; MĖLICH, 2014) no tiene que ver con las leyes, las normas o los valores, sino con tratar al otro adecuadamente. Y no puede haber un manual o una moral que nos explique cómo tratar al otro con cuidado, 
con cariño, con tiempo, con tacto, con afecto, con amor. No puede haber recetas sobre cómo tenemos que ser hospitalarios porque, como cada otro es diferente, la respuesta que demos será situacional y extraordinaria. La ética es colocarse al lado del que sufre y ayudarle en su sufrimiento, no se basa en imperativos, al contrario, para ser capaces de responder a la singularidad del otro y del acontecimiento necesitamos transitar por fuera de toda ley y norma pautadas por un sistema de valores. Y además, necesitamos hacerlo gratuitamente (SKLIAR, 2010), o sea, sin esperar nada a cambio (ni reconocimiento, ni recompensa), en un sí desprendido de cualquier retribución hacia el Yo que, en ese momento, ha sido descentrado de la propia subjetividad y reemplazado por el otro.

Recibir al otro implica asumir que la respuesta que demos nunca será lo suficientemente adecuada. Siempre nos quedará la incógnita de si habremos estado a la altura de lo que él o ella nos pedía. Y es que cuando alguien sufre, hasta su silencio reclama nuestra atención: somos llamados a responder. El silencio está cargado de significado, al contrario que la incomunicación del mutismo. Escúchame, dice un rostro con ambigüedad, pero: ¿cómo interpretar a qué nos llama? Y: ¿a qué nos apela exactamente?

Por de pronto, nuestra respuesta radica en dar del propio tiempo, en detener y dilatar la temporalidad, nuestra respuesta reside en tener tiempo para escuchar al otro (DERRIDA, 1995). Porque tal vez los asuntos trascendentales de la vida requieren tiempo. Y, sin embargo, parece que ninguno de nosotros tenemos tiempo. Tiempo para preocuparnos por el estado de ánimo y por los sentimientos de los demás, tiempo para que los otros nos importen verdaderamente. Pero acoger es ser cuidadoso con la persona que tengo enfrente y decirle: estoy presente, déjame acompañarte, no te abandonaré, confía en mí.

La ética de la hospitalidad implica ver la alteridad en el otro y admitir el conflicto que me supone su radical diferencia respecto a lo propio. El inmenso problema de acoger incondicionalmente es que no acogemos a un constructo, no acogemos a un niño, a una niña, tampoco a un alumno ni a un caso o a un diagnóstico, acogemos a Rosario, a Ibrahim, a Belén, a Miguel, a Safae, a Kendi. Cuando nos encontramos delante del otro, no nos encontramos con un infante o con un estudiante, nos encontramos con Cristina o con Aitor. De entrada, lo acogemos en nuestra casa como si fuera cualquiera, lo albergamos en nuestro cuerpo como si fuera un igual, y posteriormente le preguntamos acerca de quién es, nos interesamos por su identidad y su historia en singular.

De ahí que los gestos de la hospitalidad no tengan tanto que ver con el "hacer» sino con el más fundamental y dificultoso estar ahí. Entonces, el educador sería alguien cuya presencia está presente para cobijar al otro; aunque no tenga muy definida la manera de hacerlo y no sepa muy bien lo que debería de hacer. Precisamente porque la condición humana es frágil y vulnerable, el oficio de educar es falible y no previsto, sujeto a la improvisación y al azar, por eso el gesto principal de educar es tener tiempo para el otro. Quizá lo esencial en educación no sea transmitir conocimientos, sino "dar el tiempo"; situarnos junto al otro y entregar amorosamente nuestro tiempo. Y decir: tengo tiempo, conversemos, para que el otro tenga la ocasión de subsanar algo de la finitud de su existencia (SKLIAR, 2010). Necesitamos ser acompañados porque vivir en el mundo es experimentar la ruptura y la herida, fácilmente, el acontecer en cualquier momento de la fragilidad y de la vulnerabilidad. 


\section{Referencias}

ADORNO, Theodor. Notas sobre literatura. Madrid: Akal, 2003.

AGAMBEN, Giorgio. El hombre sin contenido. Barcelona: Áltera, 2005.

ALLIAUD, Andrea. Experiencia, saber y formación. Revista de Educación, Mar del Plata, v. 1, n. 1, p. 141$157,2010$.

ARBIOL, Clara. Elementos para una pedagogía de la alteridad en la práctica de educadoras sociales. Teoría de la Educación, Salamanca, v. 30, n. 2, p. 109-129, 2018.

ARENDT, Hannah. Entre el pasado y el futuro. Barcelona: Península, 1996.

AYALA, Raquel. La relación pedagógica: en las fuentes de la experiencia educativa con Van Manen. Revista Complutense de Educación, Madrid, v. 29, n. 1, p. 27-41, 2018.

BÁRCENA, Fernando; MĖLICH, Joan Carles. La educación como acontecimiento ético. Buenos Aires: Miño y Dávila, 2014.

BIESTA, Gert. El bello riesgo de educar. Madrid: SM, 2017.

BUTLER, Judith. Vida precaria. Buenos Aires: Paidós, 2006.

CONTRERAS, José. El saber de la experiencia en la formación inicial del profesorado. Revista Interuniversitaria de Formación del Profesorado, Murcia, v. 27, n. 3, p. 125-136, 2013.

CONTRERAS, José; PÉREZ DE LARA, Nuria. La experiencia y la investigación educativa. In: CONTRERAS, José; PÉREZ DE LARA, Nuria (Ed.). Investigar la experiencia educativa. Madrid: Morata, 2010. p. 21-86.

CLANDININ, D. Jean. Engaging in narrative inquiry Walnut Creek. California: Left Coast, 2013.

DERRIDA, Jacques. Dar (el) tiempo. Barcelona: Paidós, 1995.

DERRIDA, Jacques. La hospitalidad. Buenos Aires: Paidós, 2000.

DERRIDA, Jacques. Palabra de acogida. Madrid: Trotta, 1998.

DELEUZE, Gilles. Foucault. Barcelona: Paidós, 1987.

DELEUZE, Gilles; GUATTARI, Félix. ¿Qué es la filosofía? Barcelona: Anagrama, 2013.

DEWEY, John. Democracia y educación. Madrid: Morata, 1998.

ESQUIROL, Josep María. La resistencia íntima. Barcelona: Acantilado, 2015. 
GADAMER, Hans Georg. Verdad y método I. Salamanca: Sígueme, 1977.

GARCÍA, Justin R.; LEWIS, Tyson E. Getting a grip on the classroom: from psychological to phenomenological curriculum development in teacher education programs. Curriculum Inquiry, Toronto, v. 44, n. 2, p. 141 168, 2014.

HAN, Byung-Chul. La expulsión de lo distinto. Barcelona: Herder, 2017.

HAN, Byung-Chul. La sociedad de la transparencia. Barcelona: Herder, 2013.

JAY, Martin. Cantos de experiencia. Buenos Aires: Paidós, 2009.

JORDÁN, José Antonio. La responsabilidad ética-pedagógica de los profesores-educadores: una mirada desde Max Van Manen. Revista Española de Pedagogía, Madrid, v. 73, n. 261, p. 381-396, 2015.

KORTHAGEN, Fred et al. Teaching and learning from within. New York: Routledge, 2013.

LARROSA, Jorge. Herido de realidad y en busca de realidad. In: CONTRERAS, José; PÉREZ DE LARA, Nuria (Ed.). Investigar la experiencia educativa. Madrid: Morata, 2010. p. 87-116.

LARROSA, Jorge. La experiencia de la lectura. México, DC: FCE, 2013.

LÉVINAS, Emmanuel. El tiempo y el otro. Madrid: Paidós, 1993.

LÉVINAS, Emmanuel. Ética e infinito. Madrid: Machado Libros, 2000.

LÉVINAS, Emmanuel. Fuera del sujeto. Madrid: Caparrós, 1997.

LÉVINAS, Emmanuel. Humanismo del otro hombre. México, DC: Siglo XXI, 2005.

LÉVINAS, Emmanuel. Totalidad e infinito. Salamanca: Sígueme, 1977.

LUKÁCS, Georg. El alma y las formas. Barcelona: Grijalbo, 1970.

MASSCHELEIN, Jan; SIMONS, Marteen. Defensa de la escuela. Buenos Aires: Miño y Dávila, 2014.

MíNGUEZ VALLEJOS, Ramón. La responsabilidad educativa en tiempo de crisis. Edetania, Murcia, n. 42, p. 107-125, 2012.

NODDINGS, Nel. Caring: a feminine approach to ethics and moral education. Berkeley: U.C. Press, 2003.

OKUDA, Mayumi; GÓMEZ, Carlos. Métodos en investigación cualitativa: triangulación. Revista Colombiana de Psiquiatría, Bogotá, v. 34, n. 1, p. 118-124, 2005.

PATOCKA, Jan. El movimiento de la existencia humana. Madrid: Encuentro, 2004. 
SIERRA, José Eduardo; BLANCO, Nieves. El aprendizaje de la escucha en la investigación educativa. Qualitative Research in Education, Barcelona, v. 6, n. 3, p. 303-326, 2017.

SKLIAR, Carlos. Los sentidos implicados en el estar-juntos de la educación. Revista Educación y Pedagogía, Antioquia, v. 22, n. 56, p. 101-111, 2010.

SLOTERDIJK, Peter. Esferas I. Madrid: Siruela, 2014.

VAN MANEN, Max. El tono en la enseñanza. Barcelona: Paidós, 2015.

VAN MANEN, Max. Investigación educativa y experiencia vivida. Barcelona: Idea Books, 2003.

ZAMBRANO, María. Notas de un método. Madrid: Tecnos, 2011.

Recibido en: 19.02.2019

Revisado en: 08.05.2019

Aprobado en: 04.06.2019

Daniel Gómez Ramos es doctor en Educación y Sociedad por la Universidad de Barcelona (España). Máster en Investigación y Cambio Educativo por la misma universidad. Educador social y Técnico en Integración Social por la Universidad de Valencia (España). 